\title{
Neglect of legal statute influence on health outcomes in studies about human cannabis use
}

Thiago C Moulin ${ }^{1}$, José A. J. Alves², João R L Menezes ${ }^{3 *}$

1. Functional Pharmacology Unit, Department of Neuroscience, Uppsala University, Uppsala, SE

2. Colegiado de Bases Biológicas e da Saúde, Universidade de Brasília, Brasília, BR 3. Instituto de Ciências Biomédicas, Universidade Federal do Rio de Janeiro, Rio de Janeiro, BR

Keywords: Schizophrenia, Stress, Drug Policy, Environment, Contaminants, Pesticides, Fungi, Prohibition

Corresponding author:

João R. L. Menezes

jrlmenezes@gmail.com

Laboratório de Neuroanatomia Celular

Programa de Anatomia ICB

Bloco F - Sala 025, Prédio do Centro de Ciências da Saúde (CCS)

Universidade Federal do Rio de Janeiro

Av. Carlos Chagas Filho, Cidade Universitária - Ilha do Fundao,

Rio de Janeiro, RJ, CEP 21941-902. 


\begin{abstract}
Background: Most modern studies about human marijuana use have been made under a set of arbitrary cultural standards and policies not related to drug harm potential, loosely called Prohibition. Here we asked if potential health hazards generated by Prohibition are addressed in research design and analysis.

Methods: For this, we have searched PubMed database (from inception to December 2017) for citations of prevalent contaminants of illegal street cannabis: fungi and pesticides. In addition, we performed full text evaluation of 23 studies selected from, and including, 2 meta-analysis reviews investigating potential health hazards from cannabis use.

Results: Different combinations of the keywords cannabis, prohibition, pesticides, fungi, contaminants, cancer, schizophrenia, psychosis, show that these words coincide in less than $1 \%$ of the cannabis human studies within the database. In the scope of 141 abstracts in which the terms, cannabis and pesticides coincide, none is directed to distinguish cannabis and pesticide adverse effects on CNS. A similar picture emerges when fungi is the paired word. Full text evaluation shows that all but one of the studies analyzed, completely neglect or comment on the nature of cannabis source, legal status, or contamination as a confounding factor.

Discussion: Our results show a potential bias on scientific investigation that may affect data reliability in informing about the health hazards of cannabis use. This finding suggests that other aspects of the Prohibition environment may also go unacknowledged.

Conclusion: Prohibition related health risks usually go unacknowledged and unaccounted for in biomedical research on Cannabis.
\end{abstract}




\section{Introduction}

In 1961, the United Nations Single Convention on Narcotic Drugs banned Cannabis Sp from international commerce, along with two other third world traditional cultivars. Signatory countries agreed to terminate all cannabis use within their borders, except for medical and scientific purposes (UN Convention 1961; Room and Reuter, 2012). The follow-up sister treaties maintained, and increased this interdiction, directly suggesting that countries applied intervenient criminal justice to reduce supply and demand (UN Conventions 71, 88). The 1961 treaty is a culmination of political and sociological phenomena that can be traced from the end of the XIX century onwards, described elsewhere (Kendell, 2002; Bewley-Taylor et al., 2014; Fischer et al., 2015; Hall, 2017), mostly related to post-colonialist politics and with a strong ethnic-racial bias (Mena and Hobbs, 2009). Here we will call this general policy based on interdiction and criminalization as Prohibition.

Prohibition can be defined as a public policy based on the belief that drug use and its potential harms can be avoided by imposed abstinence and criminalization of supply, when not, of demand also. In its purest sense, it involves a mechanism of social exclusion to punish unwanted or unacceptable behavior. Social exclusion as a response to drug abuse behavior has been described previously for herd or other social animals (Siegel, 2005). It can be understood as a conceptual framework that manifests in many forms and has been applied many times before as a public policy to quell unwanted drug use by different societies and for different drugs (Mena and Hobbs, 2009). The United Nations Treaties for Narcotic control are just one example of such manifestations, and despite the unanimity of most world Nations (presently 186 signatory nations), this belief is not founded in any reliable and rigorous evidence.

From its inception (circa 1930, for most countries in the League of Nations) cannabis Prohibition policy was made with the claim of protecting public health. However, no rigorous randomized controlled trials (RCTs) to evaluate safety and efficacy were undertaken then, nor presently, that could justify this policy. This contrasts significantly with the usual standards required to introduce a new public healthcare policy, such as vaccination, for example. Notwithstanding the lack of solid evidence, this policy is widely implemented and has led to the use of methods that are strange to any other public health instrument and are more acquainted with financial and property protection. These can include criminal penalties, incarceration, use of police force, and sometimes even harsher measures. Prohibition efficacy is contested, controversial, and stands on feeble evidence (Room and Reuter, 2012). Furthermore, such policies have many unintended consequences on human rights with the criminalization of selective behaviors and ethnic groups (Strang et al., 2012), irrational drug regulatory marks unrelated to harm (Nutt et al., 2007; 2010), and obstruction of scientific research (Nutt et al., 2013). Other unintended consequences of the treaties, such as violence, corruption, are widely recognized, even by the UN proper (WDR, 2009).

Given its xenophobic or otherwise racist origins, its lack of rigorous evidence of safety and efficacy, and its blatant infringement of human rights, the endurance of cannabis prohibitionist policies is somewhat surprising. This unpredictable success supposedly rests on some characteristic psychological trait that leads to a phobia of foreign culture drugs (Mena and Hobbs, 2009). Here we will assume that Prohibitionist policies are maintained 
in part through the manipulation of this phobic trait by governmental and private entities with biased information and propaganda, and the use of unsubstantiated claims or even false information to justify the illicit nature of cannabis (Bewley-Taylor et al., 2014; Kendall, 2002; MacCoun, 2001; Fischer et al., 2015). Most currently working scientists must have also been exposed since childhood to this kind of biased misinformation. Here we ask if this cultural influence introduces bias and affects the objectivity of scientific inquiry about cannabis use, as suggested previously (Macleod e Hickman, 2010; Temple et al., 2011).

Due to its high prevalence, it is important to determine the health effects and impacts of cannabis use on the human body, sane or diseased. However, in the last fifty years, cannabis is mostly obtained in illegal marginalized settings, without any quality control and with many social and individual health risks. This led us to ask if studies addressing the health consequences of cannabis use controls for the pervasive Prohibition environment. Can we differentiate the resulting outcomes attributed to cannabis compounds from those related to the Prohibition environment?

The Prohibition environment is complex, multilayered, and difficult to model and control. Because of its ubiquity, the Prohibition environment cannot be adequately controlled in population studies. However difficult to measure, its effects are partially predictable. These potential harms may arise from social factors related to the black market, violence, poverty, incarceration, social stress, social exclusion, or other unique cultural response to drug use, direct metabolic effects of street drug use without any quality control, and ignorance of drug purity and potency. Individual responses to this environment can also be difficult to predict without large, well-conducted RCTs with a controlled population due to the physiological, psychological, and genetic diversity of the human population. Due to a variable degree of relaxation of drug laws between countries and regions, some natural experiments are possible (Degenhardt et al., 2010; Room and Reuter, 2012; Vuolo, 2013), but criminalization is still the norm, which makes interpretation more complex. Holland's tolerance policy is an example. Although the everyday user is kept distant from criminal activity, cannabis is still illegal, and its production is associated with a criminal market, with little or no quality control, containing chemical and microbiological contaminants. Thus, contaminants present in street cannabis can be a standard and objective indicator for cannabis prohibition in any of its diverse settings.

By using a directed literature review, we asked if potential adverse effects of Prohibition over health are taken into account in research design and analysis. For this, we have used contamination by fungi and pesticides as a proxy for Prohibition. Our initial approach was to cross-reference cannabis to related words such as prohibition, pesticides, fungi, and contaminants in the PubMed database, which resulted in a relatively low number of papers. By examining the abstracts recovered from the combination of cannabis with either pesticide or fungi, we found that none were directed to differentiate these contaminants' health effects from those that would result from uncontaminated cannabis. Mentions to possible synergistic effects of prohibition or contaminants with other components of cannabis were also absent in the abstracts. This suggests that investigators seem to neglect cannabis contamination health risks, and as a corollary, prohibition. As a proof-of-concept, we have analyzed two recent meta-analysis reviews about the potential adverse effects of cannabis use, such as the increased risk for schizophrenia and morphological brain 
alterations, and 21 studies cited therein. We also found within this set negligible or absent mention of Prohibition by itself as a possible health-determining factor. As predicted, our data reveal a potential bias that may affect data reliability about the health hazards of cannabis use.

\section{Methods}

\subsection{Search strategy, prevalence of studies, and Venn diagrams}

To obtain an overall estimate the relative amounts of articles investigating health risks and outcomes generated by Prohibition, we first performed a PubMed search for the broad term "cannabis OR marijuana" which yielded 26273 results. Then, we performed an individual search for each of the terms we defined as related to 1. Illegality-related health hazards: "(cannabis OR marijuana) AND fungi", "AND pesticide*", "AND contaminant*"; 2. Main health outcomes: "(cannabis OR marijuana) AND schizophrenia", "AND psychosis", "AND cancer"; and 3. General Prohibition-related discussions: "(cannabis OR marijuana) AND prohibition". The percentage of articles found for each specific term was then calculated in relation the broad search (Table 1). The search results were also used in the InteractiVenn online software (Heberle et al., 2015), which generated the Venn diagrams shown in Figure 1. Most searches were performed through January 2018. All searches searches were limited to December $31^{\text {st }}, 2017$. All the search results files can be found as Supplementary Material.

\subsection{Frequency of terms}

For the analysis of the most frequent terms, the output from the PubMed search "cannabis or marijuana" was analyzed using the VosViewer software (Van Eck and Waltman, 2011). Briefly, this software identified the terms contained on title, abstract and keyword list from the articles, and accounted for repetitions among studies. The first 100 most frequent terms were manually categorized as showed in Table 2 . The complete list of words can be found as Supplementary Material.

\subsection{Screening of abstracts}

To characterize the topics discussed by articles considering contaminants, we retrieved abstracts from the PubMed search combining pesticides, fungi, with cannabis. Using the Abstrackr online software (Wallace et al. 2012), we evaluated if the studies approached discussed the illegal status of cannabis and possible health outcome. First, abstracts were scrutinized by one researcher (JRLM) and classified as: human and non-human study; epidemiological surveys; experimental, toxicological or clinical studies (any type); and reviews. Abstracts were then examined for any mention of cannabis contaminants and their health consequences for human use. A second researcher (JAJA) reviewed the output lists.

\subsection{Full-text evaluation}

A full-text screening was performed in articles within two meta-analytic studies, which were selected non-randomly by one of the authors (JRLM), using the following criteria: 1. A rigorous selection protocol for the studies used to conduct the meta-analysis, and designed to settle understanding on a specific topic; 2. Popular articles and that had news media exposure; and 3. Designed to evaluate the possible adverse effects of non-medical 
cannabis use. Only full texts of peer-reviewed published studies that contributed for the meta-analysis were included. Datasets reports were not included. Studies were examined for any mention of prohibition, illicit cannabis status, and its consequences, such as contaminants and social distress.

\section{Results}

\subsection{Popular terms in cannabis research}

We can observe that within the entries in PubMed related to cannabis, words associated with its illicit status are surprisingly underrepresented when compared with the frequency of all words used in cannabis studies (Table 1).

\subsection{Prevalence of terms related to health risk or illicit status}

To identify papers that might have tackled the illicit nature of cannabis and its health risks, we combined illicit-status related words (prohibition, pesticide, fungi, contamination) with some health hazards terms usually related to cannabis (psychosis, schizophrenia, cancer). Studies citing illicit status-related words are less prevalent in the database when compared to psychiatric disorders terms, such as psychosis and schizophrenia (Table 2), with little or no co-occurrence (Figure 1A). Almost no overlap occurs between illict-related words and these psychiatric disorders related terms (Figure 1B). In a similar manner, only a small fraction of the search results with the term 'cancer' (902), also contained the terms 'pesticide' (9) or 'fungi' (42) (Data not shown).

\subsection{Screening of articles on cannabis contamination}

We have screened the abstracts that combined cannabis with fungi (342 studies) or pesticides (141 studies) to detect if any tackled the influence of the illegal status of cannabis in health outcomes. From the fungi search list, after the exclusion of non-human studies, 223 abstracts were retrieved, the majority about diseases unrelated to cannabis. Only 22 studies reported on health issues related to fungi and cannabis use or production. Of these 7 were case reports; 1 clinical study, 6 without abstracts; 2 were about non-fungal contamination. Of these 22 , only 4 referred to the illicit nature of cannabis source, and only one mentioned the black market as a source of contamination. No study attempted to differentiate the adverse effects of cannabis compounds from its fungal contamination within the abstract.

With pesticide articles the picture is not much different. Only 31 of the 141 studies were about cannabis contamination. More than half of these (17) were related to the 70-80's Paraquat affair (Landrigan et al., 1983), mostly editorial comments, with no abstract. Of the remaining abstracts, only 2 refer to the black market as an important source of contamination and its health consequences. Of these, one specifically (McPartland and Pruitt, 1997) called attention for the possible interpretation of data from contaminated cannabis.

Lastly, we compiled a list of papers recovered from the searches with pesticides or fungi, that had a distinct discussion of the putative health effects of contaminated cannabis on 
organic systems (Table 3). There is a notable absence of interest in the effects of contaminated cannabis on the nervous system.

\subsection{Full-text evaluation of meta-analytic studies}

Even though we have detected little mention in the abstracts about the influence of illicit cannabis nature, it is possible that within the text authors could still approach and recognize prohibition and its consequences as a confounding risk factor. For this, we decided to screen thoroughly a reduced set of papers pre-selected by relevance and rigorous study design. Relevance was judged subjectively from media exposure, and meta-analytical studies were taken as having rigorous study design. Using these and other criteria (see Methods), two meta-analytical reviews were selected (Weiland et al., 2015; Marconi et al., 2016) and studies included in their meta-analysis were screened (Table 4). We considered information such as the source of cannabis, mode of acquisition, contact with criminal activity and policing activities at supply sites, and cannabis chemical components, such as phytocannabinoids and terpenes, fungi or pesticides. We also searched to see if any of these items are added as possible confounding factors or at least acknowledged as relevant but ignored variables.

The selected studies involved human subjects recruited from the general population, with different recruiting strategies, in 8 countries, 13 different cities from 1990 to 2015. Although regions varied in respect of cannabis regulatory marks, all were conducted under the umbrella of the unregulated cannabis market. Some were longitudinal cohort studies, and others were cross-sectional studies. Most studies controlled for sex, age, and some for sociodemographic confounders, ethnicity, use of other drugs, etc. All studies were designed to test the supposed adverse effects of non-medical cannabis use. The outcomes analyzed in these two sets of references were the incidence of psychotic symptoms or schizophrenia clinical diagnosis (Marconi et al., 2017; 11) or regional brain morphological alterations in imaging studies (Weiland et al. 2015; 12).

None of the studies identified the source of cannabis used. None approached the environment where cannabis was used. Most registered the amount of cannabis use indirectly by the subject report. Only one set of these studies tried to identify the potency of cannabis consumed (Di Forti et al., 2009, 2014), using an indirect strategy of deducing potency from police reporting, without any further phytochemical and microbiological analyses. With one notable exemption (Weiland et al., 2015), none of the studies approached or mentioned the consequences of the illegal market, contact with criminality, and other aspects of users in conflict with the law to understand the effects of cannabis use. We found no specific mentions of pesticides, contaminants, or other variables due to the illegal market. Finally, all studies failed to include a discussion about the possible effects of the illegal, unregulated market, again with a partial exception of the Weiland study.

\section{Discussion}

Our findings reveal apparent neglect about the potential health harms of cannabis prohibition in studies compiled in the PubMed database about human cannabis use since database inception until December 2017. This neglect is somewhat surprising, as the 
majority of those studies analyzed the consumption effects of cannabis that was obtained illegally or of otherwise unknown source and constituents. By searching the content of the abstracts of articles about fungi or pesticides contamination, we found little or no indication that the Prohibition environment is taken into account or discussed as a possible confounding or contributing factor to the outcomes of drug use. Biomedical researchers seem to regard prohibition as neutral, without any detrimental effect over cannabis users or their surroundings. However, since even this premise goes unacknowledged, we have interpreted it as a hidden bias possibly borne from the exposure of researchers to a prohibitionist environment. It could be described as a form of intrinsic cognitive neglect, similar to the retina's blind spot. Alternatively, this neglect could be implicitly driven by biased grant decision-making policy, as suggested by some NGOs in favor of legislative changes, such as MAPS (Frood, 2007). We have not addressed this issue but given the diversity of financing agents involved with cannabis research, with many different national origins, it makes a concerted action rather unlikely.

It has been recognized before that prohibition hampers scientific investigation (Nutt et al., 2013), introducing barriers in many forms, such as complex bureaucracy, security requirements, or lack of directed financing. These barriers, although not insurmountable, seem to undermine researchers' enthusiasm on the subject. It also represents a barrier for randomized controlled trials to evaluate non-medical cannabis long-term use effects, since cannabis used in these settings are rarely of pharmaceutical grade. Here, we introduce another layer of complexity, the subjective influence of a prohibitionist environment that seems to hamper research design and blinds the experimenter, reviewers, and financing agencies for requiring adequate controls. We find this neglect unreasonable, revealing an intrinsic bias that stands out in an otherwise rigorous methodological research environment and culture.

Cannabis criminal legal status, and the environment it engenders, can potentially generate a diverse array of health harms rarely acknowledged in biomedical research (Hall, 2017; Shakoor et al., 2015; Proal et al., 2013; Temple et al., 2010; McLeod et al., 2004). However, the Prohibition environment is complex and heterogeneous across distinct geographical regions, from the neighborhood to national and international scales, regarding cultural, sociopolitical, and legislative aspects at each specific geographical region. These potential harms can arise from violence, social exclusion, incarceration, extortion, slave labor, and sexual exploitation of users or their relatives. It can also arise from individual vulnerabilities to unwanted social consequences of Prohibitionist policies such as: exposure of users, adults or adolescents, to criminal activities; user avoidance of health services; and conflict with parental, educational, and police authorities. Social fear, although variable in intensity and eliciting different individual responses, is a constant aspect of the illicit drug use and may affect health in a manner akin to poverty and social exclusion (Murali e Oyebode, 2004; Santiago et al., 2013; Reiss, 2013). Social fear can manifest as the fear of incarceration, criminal or parental punishments, loss of work opportunities, or other forms of social and familial exclusion. This prohibition created fear, and the stress derived from it has the potential to contribute to adverse outcomes from drug use and may fall under the umbrella of the Social Causation Hypothesis (Warren, 2009).

Another constant aspect of Prohibition is the contamination of drug preparations of the illicit market that are not subjected to rigorous quality control. Even in the licit market of 
plant products, contamination is a well-known issue in public health, leading to several regulatory and overseeing agencies. Due to Prohibition, no such agency or attention is universally available for cannabis. Due to the difficulty of establishing efficient regulatory marks, contamination is reported even in the recently legal cannabis markets (Stone, 2014; McKernan et al., 2016, Dryburgh, 2018). Cannabis potential contamination of cannabis by fungi, pesticides, and heavy metals is also known in the scientific and grey literature (Kagen et al., 1983; Sullivan et al., 2013; Lanaro et al., 2015; McLaren et al., 2008, Cole et al., 2010). These pieces of evidence, coupled to the well-documented late 1970's ordeal of paraquat contamination of Mexican and US illicit market cannabis, and its potential health consequences (Landrigan et al., 1983), makes the lack of acknowledgment of cannabis contaminants in our literature search rather unexpected.

It is possible that our limited research strategy may have missed studies that consider Prohibition variables in study design. If we had extended our study to other databases, we might have retrieved more studies focusing on cannabis contamination and its possible health effects. However, we argue that the PubMed database is representative of the biomedical field, and given the ubiquity of cannabis prohibition, it is expected that the consequences of its illicit status should be addressed often, independently of the database. In addition, a recent systematic review of cannabis contamination, with a larger database set, has also retrieved few studies about the contamination effect on cannabis use (Dryburgh et al., 2018). Also, it is true that if we had extended our exhaustive analysis to a wider set of studies, limited here to 23 papers, we might have found more papers taking the full spectrum of the illicit environment in consideration. In fact, the concept of illegal market as a source of adverse effects from cannabis use has been raised before (McLeod et al., 2004; Temple et al., 2010; Sullivan et al., 1983), found in few of the retrieved abstracts of the pesticide and fungi search (Kurup et al., 1983; McPartland and Pruitt, 1997), and also in a recent review outside of the period of investigation (Dryburgh et al., 2018). We are also aware of at least one example in the literature of mentions about the possible role of the illegal market in outcome (Fergusson et al, 2005), but these seem few and far between. Given the rapidly evolving change in attitude towards cannabis in many countries, awareness of cannabis contaminants may become more widespread, if only for the establishment of industry standards. Recently, Leung and collaborators (2019) argued for the possibility that contaminants can underlie adverse outcomes from prenatal exposure to cannabis.

It is arguable that previous strong anecdotal and experimental evidence that THC is sufficient to induce paranoid ideation (Freeman et al., 2014), especially in susceptible subjects (D'Souza et al., 2005), may have misled investigators to neglect the effects of Prohibition and associated cannabis contaminations on development of psychotic disorders. The same cannot be said about possible gross anatomical changes attributed to neurotoxicity of compounds of street cannabis, attributed solely to phytocannabinoids and their metabolites, even though street cannabis is a heterogeneous potentially neurotoxic mixture (Dryburgh et al., 2018), often obtained in a stressful environment and from illicit source. Another possible explanation for the implicit dismissal of Prohibition as an agent for adverse outcomes is the complexity imposed for experimental investigation. Illicit cannabis contamination and phytochemical profile may vary in composition temporally and geographically, combined with a wide spectrum of potentially hazardous agents present in undetermined amounts. This list (see, Cole et al., 2010) can include potentially 
hazardous agents such as illicit pesticides used in unregulated concentrations, many different types of microbiological agents, mostly fungi, and heavy metals, the latter which we have not addressed in this review. Furthermore, fungi, heavy metals and pesticides intoxication have been related to psychiatric or neurological disorders, acting either directly onto the CNS or through peripheral inflammation and cytokine mediated CNS effects (Ismael et al., 2017; Yan et al., 2016; Stallones and Beseler, 2016; Harrison and Ross, 2016; Dryburgh et al., 2018; Liew and Mohd-Redzwan 2018; McCusker and Kelley, 2013; Severance et al., 2016). Here we argue that it is plausible that cannabis contaminants may influence outcomes usually attributed exclusively to the action of phytocannabinoids, such as the induction of psychotic disorders, schizophrenia or gross morphological changes due to direct neurotoxicity, often from chronic and cumulative exposure to contaminants during adolescence.

Furthermore, the Prohibition environment, with its associated social stress and exclusion, may be psychotogenic as, or act synergistically with, any of the usual risk factors ascribed to psychotic diseases such as trauma, urbanicity, and ethnic minority participation (van Os et al., 2010). These effects of Prohibition, psychological, infectious or toxic, can act in synergy to phytocannabinoids leading to adverse outcomes. For organophosphates, the most widely used agents for pest control, there are several potential molecular pathways for interaction with the endocannabinoid system (Nomura et al., 2008; Carr et al., 2013, 2014). Thus, exposure to the Prohibition environment at any stage during human development can co-occur with any potential schizophrenia triggering factors, such as trauma, social defeat, inflammation, social cognition, within the framework of the multiple hit hypothesis for schizophrenia pathogenesis (Davis et al., 2016). Thus, although compelling, Prohibition and its multiple consequences are not considered in the set of 23 studies thoroughly analyzed, and rarely in the majority of biomedical literature. This neglect is especially striking within the studies that used the GAP data (Marconi et al., 2016; Di Forti et al., 2009, 2014), which associated increased frequency of use, and/or high potency street cannabis, to increased psychotic symptoms and disorders. Since all cannabis used by subjects in these studies, were from illegal markets, increase in cannabis use should obligatory be accompanied with an increase exposure to contaminants, and to the illicit environment. Both relationships went unacknowledged within these studies.

Our data are in conformity with our initial hypothesis that the pervasive secular Prohibition culture influences scientist's objectivity (Macleod e Hickman, 2010; Temple et al, 2010). However, we can only speculate about the mechanism that could explain the origin of this cognitive neglect, for our data sheds little light on how Prohibition culture creates such pervasive bias. It is important to put in perspective that drug use is the result of a long evolutionary history of plant and animal interaction, with many complex developments (Hagen et al., 2013), human social organizations possibly included. Drug related bias and social exclusion may be the human expression of an instinctive, constitutive biological mechanism of social interaction, somewhat similar to those observed in other social animals (Siegel, 2005). We are reluctant however, to bridge the enormous complexity of novel human social and cultural interaction and the behavior of animals with limited inter individual communication repertoire. Despite the lack of a reasonable mechanism, once detected is imperative to acknowledge the existence of this environment-derived bias so to understand its influence in past, present and future research about the medical and nonmedical use of cannabis, and related cannabinoids and terpenoids. 


\section{References}

Arseneault L, Cannon M, Poulton R, Murray R, Caspi A, Moffitt TE. (2002). Cannabis use in adolescence and risk for adult psychosis: longitudinal prospective study. $B M J$. 325(7374):1212-1213. doi:10.1136/bmj.325.7374.1212

Ashtari M, Avants B, Cyckowski L, et al. (2011). Medial temporal structures and memory functions in adolescents with heavy cannabis use. J Psychiatr Res. 45(8):10551066. doi:10.1016/j.jpsychires.2011.01.004

Bewley-Taylor DR, Blickman T, Jelsma M. (2014). The rise and decline of cannabis prohibition. In D. Aronson (Ed.), Jubels, Amsterdam: Global Drug Policy Observatory.

Block RI, O'Leary DS, Ehrhardt JC, et al. (2000). Effects of frequent marijuana use on brain tissue volume and composition. Neuroreport 11(3):491-496.

doi:10.1097/00001756-200002280-00013

Carr RL, Adams AL, Kepler DR, Ward AB, Ross MK. (2013). Induction of endocannabinoid levels in juvenile rat brain following developmental chlorpyrifos exposure. Toxicol. Sci. 135 (1): 193-201. doi: 10.1093/toxsci/kft126. Epub 2013 Jun 12

Carr RL, Graves CA, Mangum LC, Nail CA, Ross MK. (2014). Low level chlorpyrifos exposure increases anandamide accumulation in juvenile rat brain in the absence of brain cholinesterase inhibition. Neurotoxicology 43: 82-89. doi:

10.1016/j.neuro.2013.12.009. Epub 2013 Dec 25

Cole C, Jones L, McVeigh Jim, Kicman A, Syed Q, Bellis MA. (2010). CUT: a guide to adulterants, bulking agents and other contaminants found in illicit drugs. Publisher: Centre for Public Health - Faculty of Health and Applied Social Sciences - Liverpool John Moores University.

Cousijn J, Wiers RW, Ridderinkhof KR, van den Brink W, Veltman DJ, Goudriaan AE. (2012). Grey matter alterations associated with cannabis use: results of a VBM study in heavy cannabis users and healthy controls. Neuroimage. 59(4):3845-3851. doi:10.1016/j.neuroimage.2011.09.046

Davis J, Eyre H, Jacka FN, Dodd S, Dean O, McEwen S, Debnath M, McGrath J, Maes M, Amminger P, McGorry PD, Pantelis C, Berk M. (2016). A review of vulnerability and risks for schizophrenia: Beyond the two hit hypothesis. Neuroscience and Biobehavioral Reviews 65: 185-194. doi: 10.1016/j.neubiorev.2016.03.017. Epub 2016 Apr 9.

D’Souza DC, Abi-Saab WM, Madonick S, Forselius-Bielen K, Doersch A, Braley G, Gueorguieva R, Cooper TB, Krystal JH. (2005). Delta-9-tetrahydrocannabinol effects in schizophrenia: implications for cognition, psychosis, and addiction. Biol Psychiatry. 57: 594-608. doi: 10.1016/j.biopsych.2004.12.006

Degenhardt L, Chiu W, Sampson N, Kessler RC, Anthony JC, Angermeyer M, Bruffaerts R, de Girolamo G, Gureje O, Huang Y, Karam A, Kostyuchenko S, Lepine JP, Mora MEM, Neumark Y, Ormel J, Pinto-Meza A, Posada-Villa J, Stein DJ, Takeshima T, Wells JE. (2008). Toward a Global View of Alcohol, Tobacco, Cannabis, and Cocaine 
Use: Findings from the WHO World Mental Health Surveys. PLoS Med 5(7):e141. doi:10.1371

Degenhardt L, Hall W. (2001). The association between psychosis and problematical drug use among Australian adults: findings from the National Survey of Mental Health and Well-Being. Psychol Med. 31(4):659-668. doi:10.1017/s0033291701003865

Dryburgh LM, Bolan NS, Grof CPL, Galettis P, Schneider J, Lucas CJ, Martin JH. (2018). Cannabis contaminants: sources, distribution, human toxicity and pharmacologic effects. Br J Clin Pharmacol. 84(11): 2468-2476. doi: 10.1111/bcp.13695. Epub 2018 Aug 1

Di Forti M, Morgan C, Dazzan P, Pariante C, Mondelli V, Marques TR, Handley R, Luzi S, Russo M, Paparelli A, Butt A, Stilo SA, Wiffen B, Powell J, Murray RM. (2009). High-potency cannabis and the risk of psychosis. Br J Psychiatry. 195: 488-491. doi: 10.1192/bjp.bp.109.064220

Di Forti M, Sallis H, Allegri F, Trotta A, Ferraro L, Stilo SA, Marconi A, La Cascia C, Reis Marques T, Pariante C, Dazzan P, Mondelli V, Paparelli A, Kolliakou A, Prata D, Gaughran F, David AS, Morgan C, Stahl D, Khondoker M, MacCabe JH, Murray RM. (2014). Daily use, especially of high-potency cannabis, drives the earlier onset of psychosis in cannabis users. Schizophr Bull. 40:1509-1517. doi: 10.1093/schbul/sbt181. Epub 2013 Dec 17.

Fergusson DM, Boden JM, Horwood LJ. (2006). Cannabis use and other illicit drug use: testing the cannabis gateway hypothesis. Addiction. 101(4): 556-569. doi: 10.1111/j.1360-0443.2005.01322.x.

Freeman D, Dunn G, Murray RM, Evans N, Lister R, Antley A, Slater M, Godlewska B, Cornish R, Williams J, Di Simplicio M, Igoumenou A, Brenneisen R, Tunbridge EM, Harrison PJ, Harmer CJ, Cowen P, Morrison PD. (2015). How cannabis causes paranoia: using the intravenous administration of $\Delta 9$-tetrahydrocannabinol (THC) to identify key cognitive mechanisms leading to paranoia. Schizophr Bull. 41(2):391-399. doi: 10.1093/schbul/sbu098. Epub 2014 Jul 15.

Fischer B, Kuganesan S, Room R. (2015). Medical Marijuana programs: implications for cannabis control policy--observations from Canada. Int J Drug Policy. 26(1):15-9. doi: 10.1016/j.drugpo.2014.09.007. Epub 2014 Sep 22.

Frood A. (2007). Scientists stir the pot for right to grow marijuana. Nat Med. 13(7):764. doi: 10.1038/nm0707-764a. Epub 2007 Jun 29.

Gilman JM, Kuster JK, Lee S, et al. (2014). Cannabis use is quantitatively associated with nucleus accumbens and amygdala abnormalities in young adult recreational users. J Neurosci. 34(16):5529-5538. doi:10.1523/JNEUROSCI.4745-13.2014

Hagen EH, Roulette CJ and Sullivan RJ. (2013). Explaining human recreational use of 'pesticides': the neuro-toxin regulation model of substance use vs.the hijack model and implications for age and sex differences in drug consumption. Front. Psychiatry 4: 142. doi: $10.3389 /$ fpsyt.2013.00142 
Hall W (2017). Alcohol and cannabis: Comparing their adverse health effects and regulatory regimes. Int J Drug Policy 42:57-62. doi: 10.1016/j.drugpo.2016.10.021. Epub 2016 Nov 28.

Harrison V, Mackenzie Ross S. (2016). Anxiety and depression following cumulative low-level exposure to organophosphate pesticides. Environ Res. 151: 528-536. doi: 10.1016/j.envres.2016.08.020. Epub 2016 Aug 27.

Heberle, H., Meirelles, G.V., da Silva, F.R. Telles, G.P., Minghim R. (2015). InteractiVenn: a web-based tool for the analysis of sets through Venn diagrams. $B M C$ Bioinformatics 16, 169. https://doi.org/10.1186/s12859-015-0611-3

Henquet C, Murray R, Linszen D, van Os J. (2005). The environment and schizophrenia: the role of cannabis use. Schizophr Bull. 2005;31(3):608-612. doi:10.1093/schbul/sbi027

Ismail AA, Wang K, Olson JR, Bonnerd MR, Hendy O, Rasoul GA, and Rohlman DS. (2017). The impact of repeated organophosphorus pesticide exposure on biomarkers and neurobehavioral outcomes among adolescent pesticide applicators. J Toxicol Environ Health A. 80(10-12): 542-555. doi:10.1080/15287394.2017.1362612

Kagen SL, Kurup VP, Sohnle PG, Fink JN. (1983). Marijuana smoking and fungal sensitization. J Allergy Clin Immunol. 71(4):389-93. doi: 10.1016/0091-6749(83)900672.

Kendell R. (2002). Cannabis condemned: the proscription of Indian hemp. Addiction 98:143-151. doi: 10.1046/j.1360-0443.2003.00273.x.

Kurup VP, Resnick A, Kagen SL, Cohen SH, Fink JN. (1983). Allergenic fungi and actinomycetes in smoking materials and their health implications. Mycopathologia 82(1):61-64. doi: 10.1007/BF00436948.

Lanaro R, Costa JL, Cazenave SO, Zanolli-Filho LA, Tavares MF, Chasin AA. (2015). Determination of herbicides paraquat, glyphosate, and aminomethylphosphonic acid in marijuana samples by capillary electrophoresis. J Forensic Sci. 60 Suppl 1:S241-7. doi: 10.1111/1556-4029.12628. Epub 2014 Nov 20.

Landrigan PJ, Powell KE, James LM, Taylor PR. (1983). Paraquat and Marijuana: Epidemiologic Risk Assessment. Amer Journal Public Health 73:784-788. doi: 10.2105/ajph.73.7.784.

Leung MCK, Silva MH, Palumbo AJ, Lohstroh PN, Koshlukova SE, DuTeaux SB. (2019). Adverse outcome pathway of developmental neurotoxicity resulting from prenatal exposures to cannabis contaminated with organophosphate pesticide residues. Reprod Toxicol. 85:12-18. doi: 10.1016/j.reprotox.2019.01.004. Epub 2019 Jan 19.

Liew W-P-P and Mohd-Redzwan S. (2018). Mycotoxin: Its Impact on Gut Health and Microbiota. Front. Cell. Infect. Microbiol. 8:60. doi: 10.3389/fcimb.2018.00060

MacCoun, R.J. (2001). American distortion of Dutch drug statistics. Soc 38, 23-26. https://doi.org/10.1007/BF02686215

Macleod J, Hickman M. (2010). How ideology shapes the evidence and the policy: what do we know about cannabis use and what should we do?. Addiction 105(8):1326-1330. doi:10.1111/j.1360-0443.2009.02846.x 
Macleod J, Oakes R, Copello A, et al. (2004). Psychological and social sequelae of cannabis and other illicit drug use by young people: a systematic review of longitudinal, general population studies. Lancet 363(9421):1579-1588. doi:10.1016/S01406736(04)16200-4

Marconi A, Di Forti M, Lewis CM, Murray RM, Vassos E. (2016). Meta-analysis of the Association Between the Level of Cannabis Use and Risk of Psychosis. Schizophr Bull. 42(5):1262-1269. doi:10.1093/schbul/sbw003

McKernan K, Spangler J, Zhang L, et al. (2015). Cannabis microbiome sequencing reveals several mycotoxic fungi native to dispensary grade Cannabis flowers. F1000Res. 4:1422. Published 2015 Dec 10. doi:10.12688/f1000research.7507.2

McLaren J, Swift W, Dillon P, Allsop S. (2008). Cannabis potency and contamination: a review of the literature. Addiction. 2008 Jul;103(7):1100-9. doi: 10.1111/j.13600443.2008.02230.x. Epub 2008 May 20.

McCusker RH, Kelley KW. (2013). Immune-neural connections: how the immune system's response to infectious agents influences behavior. J Exp Biol. 216(Pt 1):84-98. doi:10.1242/jeb.073411

McGrath J, Welham J, Scott J, et al. (2010). Association between cannabis use and psychosis-related outcomes using sibling pair analysis in a cohort of young adults. Arch Gen Psychiatry. 67(5):440-447. doi:10.1001/archgenpsychiatry.2010.6

McQueeny T, Padula CB, Price J, Medina KL, Logan P, Tapert SF. (2011). Gender effects on amygdala morphometry in adolescent marijuana users. Behav Brain Res. 224(1):128-134. doi:10.1016/j.bbr.2011.05.031

McPartland JM, Pruitt PL. (1997). Medical marijuana and its use by the immunocompromised. Altern Ther Health Med. 3(3):39-45.

Medina KL, Nagel BJ, Tapert SF. (2010). Abnormal cerebellar morphometry in abstinent adolescent marijuana users. Psychiatry Res. 182(2):152-159.

doi:10.1016/j.pscychresns.2009.12.004

Medina KL, Nagel BJ, Park A, McQueeny T, Tapert SF. (2007a). Depressive symptoms in adolescents: associations with white matter volume and marijuana use. J Child Psychol Psychiatry. 48(6):592-600. doi:10.1111/j.1469-7610.2007.01728.x

Medina KL, Schweinsburg AD, Cohen-Zion M, Nagel BJ, Tapert SF. (2007b). Effects of alcohol and combined marijuana and alcohol use during adolescence on hippocampal volume and asymmetry. Neurotoxicol Teratol. 29(1):141-152.

doi:10.1016/j.ntt.2006.10.010

Mena F, and Hobbs, R. (2010). Narcophobia: drugs prohibition and the generation of human rights abuses. Trends in Organized Crime, 13 (1): 60-74. ISSN 1084-4791

Miettunen J, Törmänen S, Murray GK, et al. (2008). Association of cannabis use with prodromal symptoms of psychosis in adolescence. Br J Psychiatry. 192(6):470-471. doi:10.1192/bjp.bp.107.045740

Murali, V., \& Oyebode, F. (2004). Poverty, social inequality and mental health. Advances in Psychiatric Treatment, 10(3), 216-224. doi:10.1192/apt.10.3.216 
Nomura DK, Blankman JL, Simon GM, Fujioka K, Issa RS, Ward AM, Cravatt BF, Casida JE. (2008). Activation of the endocannabinoid system by organophosphorus nerve agents. Nat Chem Biol. 4(6):373-8. doi: 10.1038/nchembio.86. Epub 2008 Apr 27.

Nutt D, King LA, Saulsbury W, Blakemore C. (2007). Development of a rational scale to assess the harm of drugs of potential misuse. Lancet. 369(9566):1047-1053. doi:10.1016/S0140-6736(07)60464-4

Nutt DJ, King LA, Phillips LD (2010). Independent Scientific Committee on Drugs. Drug harms in the UK: a multicriteria decision analysis. Lancet. 376(9752):1558-1565. doi:10.1016/S0140-6736(10)61462-6

Nutt DJ, King LA, Nichols DE. (2013). Effects of Schedule I drug laws on neuroscience research and treatment innovation. Nat Rev Neurosci. 14(8):577-585. doi:10.1038/nrn3530

Proal AC, Fleming J, Galvez-Buccollini JA, Delisi LE. (2014). A controlled family study of cannabis users with and without psychosis. Schizophr Res. 152(1):283-288. doi:10.1016/j.schres.2013.11.014

Reiss F. (2013). Socioeconomic inequalities and mental health problems in children and adolescents: a systematic review. Soc Sci Med. 90:24-31.

doi:10.1016/j.socscimed.2013.04.026

Room R, Reuter P. (2012). How well do international drug conventions protect public health?. Lancet. 379(9810):84-91. doi:10.1016/S0140-6736(11)61423-2

Santiago CD, Kaltman S, Miranda J. (2013). Poverty and mental health: how do lowincome adults and children fare in psychotherapy?. J Clin Psychol. 69(2):115-126. doi:10.1002/jclp.21951

Severance EG, Gressitt KL, Stallings CR, Katsafanas E, Schweinfurth LA, Savage CL, Adamos MB, Sweeney KM, Origoni AE, Khushalani S, Leweke MF, Dickerson FB, Yolken RH. (2016). Candida albicans exposures, sex specificity and cognitive deficits in schizophrenia and bipolar disorder. Schizophrenia 2: 16018;

doi:10.1038/npjschz.2016.18

Siegel, R. (2005). A bevy of beasts. Drugs in the social group. Chapter 9. In: Intoxication: the universal drive for mind-altering substances. Park Street Press, Rochester, Vt

Shakoor S, Zavos HM, McGuire P, Cardno AG, Freeman D, Ronald A. (2015). Psychotic experiences are linked to cannabis use in adolescents in the community because of common underlying environmental risk factors. Psychiatry Res. 227(2-3):144-51. doi: 10.1016/j.psychres.2015.03.041. Epub 2015 Apr 14.

Solowij N, Yücel M, Respondek C, et al. (2011). Cerebellar white-matter changes in cannabis users with and without schizophrenia. Psychol Med. 41(11):2349-2359. doi:10.1017/S003329171100050X

Stallones L, Beseler CL. (2016). Assessing the connection between organophosphate pesticide poisoning and mental health: A comparison of neuropsychological symptoms 
from clinical observations, animal models and epidemiological studies. Cortex. 74:405416. doi:10.1016/j.cortex.2015.10.002

Stone D. (2014). Cannabis, pesticides and conflicting laws: the dilemma for legalized States and implications for public health. Regul Toxicol Pharmacol. 69(3):284-8. doi: 10.1016/j.yrtph.2014.05.015. Epub 2014 May 20.

Strang J, Babor T, Caulkins J, Fischer B, Foxcroft D, Humphreys K. (2012). Drug policy and the public good: evidence for effective interventions. Lancet. 379(9810):71-83. doi:10.1016/S0140-6736(11)61674-7

Sullivan N, Elzinga S, Raber JC. (2013). Determination of pesticide residues in cannabis smoke. J Toxicol. 2013;2013:378168. doi: 10.1155/2013/378168. Epub 2013 May 12.

Temple EC, Brown RF, Hine DW. (2011). The 'grass ceiling': limitations in the literature hinder our understanding of cannabis use and its consequences. Addiction. 106(2):23844. doi: 10.1111/j.1360-0443.2010.03139.x. Epub 2010 Nov 11.

Tien AY, Anthony JC. (1990). Epidemiological analysis of alcohol and drug use as risk factors for psychotic experiences. J Nerv Ment Dis. 178(8):473-480.

Tzilos GK, Cintron CB, Wood JB, et al. (2005). Lack of hippocampal volume change in long-term heavy cannabis users. Am J Addict. 14(1):64-72.

doi:10.1080/10550490590899862

Van Eck, NJ, Waltman, L. (2011). Text mining and visualization using VOSviewer. ISSI Newsletter, 7(3), 50-54.

van Os J, Kenis G, Rutten BP. (2010). The environment and schizophrenia. Nature. 468(7321):203-212. doi:10.1038/nature09563

Vuolo M. (2013). National-level drug policy and young people's illicit drug use: a multilevel analysis of the European Union. Drug Alcohol Depend. 131(1-2):149-56. doi: 10.1016/j.drugalcdep.2012.12.012. Epub 2013 Jan 5.

Wallace BC, Small K, Brodley CE, Lau J, and Trikalinos TA. (2012). Deploying an interactive machine learning system in an evidence-based practice center: abstrackr. In Proc. of the ACM International Health Informatics Symposium (IHI), p.819--824.

Warren JR. (2009). Socioeconomic Status and Health across the Life Course: A Test of the Social Causation and Health Selection Hypotheses. Soc Forces. 87(4):2125-2153. doi:10.1353/sof.0.0219

Weiland BJ, Thayer RE, Depue BE, Sabbineni A, Bryan AD, Hutchison KE. (2015). Daily marijuana use is not associated with brain morphometric measures in adolescents or adults. J Neurosci. 35(4):1505-12. doi: 10.1523/JNEUROSCI.2946-14.2015.

Wiles NJ, Zammit S, Bebbington P, Singleton N, Meltzer H, Lewis G. (2006). Selfreported psychotic symptoms in the general population: results from the longitudinal study of the British National Psychiatric Morbidity Survey. Br J Psychiatry. 188:519526. doi:10.1192/bjp.bp.105.012179

World Drug Report. (2009). United Nations Office on Drugs and Crime. http://www.unodc.org/unodc/en/data-and-analysis/WDR-2009.html 
United Nations. Single Convention on Narcotic Drugs. UNODC [online], http://www.unodc.org/pdf/convention_1961_en.pdf(1961).

United Nations. Convention on Psychotropic Substances. UNODC [online], http://www.unodc.org/pdf/convention_1971_en.pdf(1971).

United Nations. Convention Against Illicit Traffic in Narcotic Drugs and Psychotropic Substances. UNODC [online], http://www.unodc.org/pdf/convention_1988_en.pdf (1988).

Yan, D. et al. (2016). Pesticides exposure and risk of Alzheimer's disease: a systematic review and meta-analysis. Sci. Rep. 6, 32222; doi: 10.1038/srep32222.

Yücel M, Solowij N, Respondek C, et al. (2008). Regional brain abnormalities associated with long-term heavy cannabis use. Arch Gen Psychiatry. 65(6):694-701. doi:10.1001/archpsyc.65.6.694

Zammit S, Allebeck P, Andreasson S, Lundberg I, Lewis G. (2002). Self reported cannabis use as a risk factor for schizophrenia in Swedish conscripts of 1969: historical cohort study. BMJ. 325(7374):1199. doi:10.1136/bmj.325.7374.1199

Zammit S, Owen MJ, Evans J, Heron J, Lewis G. (2011). Cannabis, COMT and psychotic experiences. Br J Psychiatry. 199(5):380-385. doi:10.1192/bjp.bp.111.091421 
FIGURE LEGEND

Figure 1. Venn diagrams showing little overlap between cannabis studies, illicitrelated keywords and common cannabis-related hazards such as psychosis and schizophrenia. A. The overlapping results between the different searches for illicit hazards-related terms shown in Table 2; and $\mathbf{B}$. The overlapping of the outcome from these terms and the results for often addressed cannabis health-risk terms. 
A

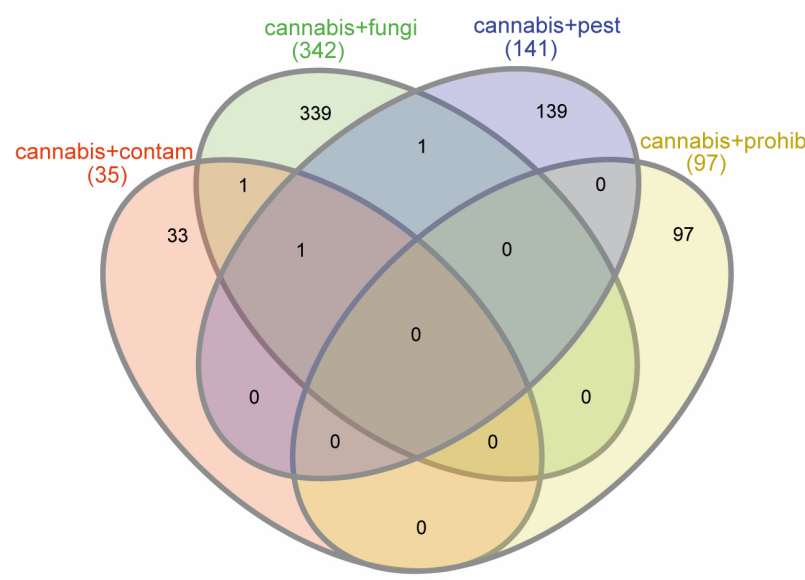

B
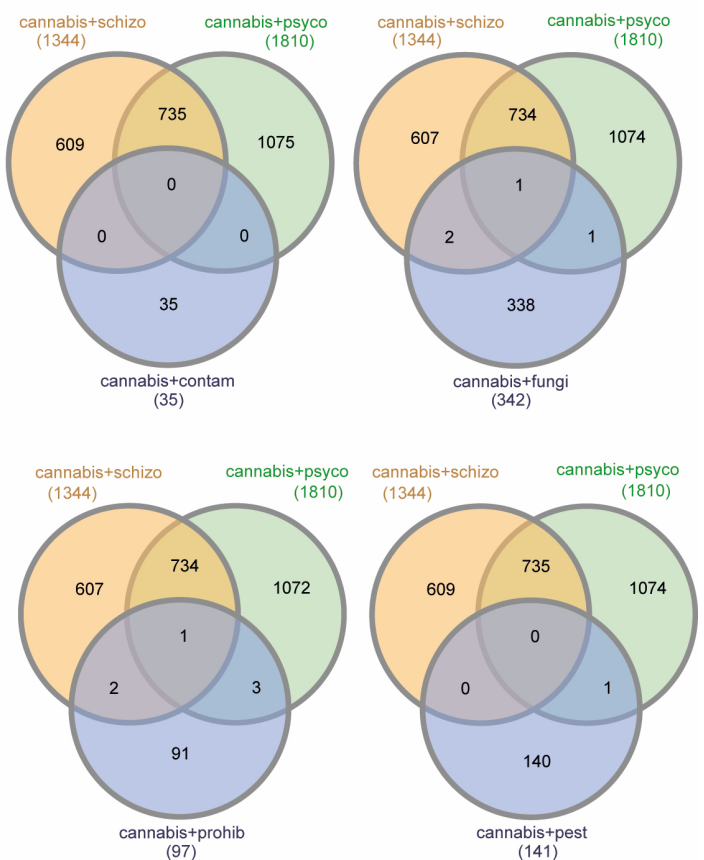
Table 1. Most frequent terms within cannabis-related articles. The top 100 expressions present on the title, abstract, and keyword list from the articles were screened and categorized (see Methods). The three most frequent terms for each category, as their relative occurrence, are shown.

\begin{tabular}{|l|l|c|}
\hline \multicolumn{1}{|c|}{ Category } & \multicolumn{1}{|c|}{ Most frequent terms } & $\begin{array}{c}\text { Occurencies (\%o of } \\
\text { papers) }\end{array}$ \\
\hline \multirow{3}{*}{ Cannabis-related terms } & "substance"/ "substance use" & $3561(13.4 \%)$ \\
& "marijuana use" & $3508(13.2 \%)$ \\
& "tetrahydrocannabinol" & $2646(9.9 \%)$ \\
\hline \multirow{3}{*}{ Drug use or addiction } & "alcohol" & $6241(23.4 \%)$ \\
& "drug use" & $3353(12.6 \%)$ \\
& "cocaine" & $2959(11.1 \%)$ \\
\hline \multirow{5}{*}{ Health-related terms } & "risk" & $3830(14.4 \%)$ \\
& "development" & $2049(7.7 \%)$ \\
& "health" & $1640(6.1 \%)$ \\
\hline \multirow{3}{*}{ General study-related terms from cannabis users } & "age" & $4002(15.0 \%)$ \\
& "user" & $3487(13.1 \%)$ \\
& "adolescent" & $3114(11.7 \%)$ \\
\hline & "effect" & $7564(28.4 \%)$ \\
\hline
\end{tabular}


Table 2. Cannabis articles associated with health risks or illicit hazards. The number of PubMed results for the chosen terms associated with cannabis health- or illicit-related risks are shown, as their relative percentages to all cannabis articles. See Methods for the exact search terms.

\begin{tabular}{|l|l|l|}
\hline Search & $\begin{array}{l}\text { Number of } \\
\text { results }\end{array}$ & $\begin{array}{l}\text { \% of "cannabis } \\
\text { OR marijuana" } \\
\text { results }\end{array}$ \\
\hline Cannabis articles & 26673 & $100 \%$ \\
\hline Cannabis articles + fungi & 342 & $1.28 \%$ \\
\hline Cannabis articles + pesticides & 141 & $0.53 \%$ \\
\hline Cannabis articles + contaminants & 35 & $0.01 \%$ \\
\hline Cannabis articles + schizophrenia & 1344 & $5.04 \%$ \\
\hline Cannabis articles + psychosis & 1810 & $6.79 \%$ \\
\hline Cannabis articles + prohibition & 97 & $0.04 \%$ \\
\hline
\end{tabular}


Table 3. List of articles directly discussing possible effects on contaminated cannabis on human physiology. After the screening abstracts retrieved when cannabis was associated with pesticides or fungi, studies discussing organic systems affected by contaminants were identified. References for this table are listed separately in the supplementary material

\begin{tabular}{|c|l|l|l|l|l|}
\hline Pesticide & First Author & Year & Country & Article Type & Systems discussed \\
\hline Brodifacoum & La Rosa FG & 1997 & USA & Case Study & Hepatic, circulatory \\
\hline \multirow{5}{*}{ Paraquat } & Turner CE & 1978 & USA & Original data & Respiratory \\
& Fairshter RD & 1978 & USA & Opinion & Respiratory \\
& Cross CE & 1978 & USA & Opinion & Respiratory \\
& Zavala DC & 1978 & USA & Original Data & Respiratory \\
& Liddle JA & 1980 & USA & Original Data & Respiratory \\
& Landrigan PJ & 1983 & USA & Original Data & Respiratory \\
\hline \multirow{5}{*}{ Various } & McPartland JM & 1997 & USA & Review & Immune \\
& Stone D & 2014 & USA & Opinion & Respiratory, dermal \\
& Russo EB & 2016 & USA & Review & Respiratory, immune, nervous \\
\hline \multirow{5}{*}{ Fungi } & First Author & Year & Country & Article Type & Systems discussed \\
\hline \multirow{2}{*}{ Alternaria } & Chusid MJ & 1975 & USA & Case Study & Respiratory \\
& Min JY & 2018 & USA & Original Data & Immune \\
\hline \multirow{5}{*}{ Aspergillus } & Lhamas R & 1978 & USA & Case Study & Respiratory \\
& Kagen SL & 1981 & USA & Opinion & Respiratory, Immune \\
& Kagen SL & 1983 & USA & Original Data & Immune \\
& Hamadeh R & 1988 & USA & Opinion & Respiratory \\
& Verweiij PE & 2000 & Netherlands & Original Data & Respiratory \\
& Cescon DW & 2008 & USA & Case Study & Respiratory \\
& McKernan K & 2015 & USA & Original Data & Respiratory, Digestive \\
\hline \multirow{5}{*}{ Fusarium } & Dimitrov M & 1990 & Bulgaria & Original Data & Respiratory \\
\hline
\end{tabular}


Table 4. Analysis of full-text reports. Two meta-analysis and studies included therein (see Methods) were evaluated for any mention of factors derived from cannabis legal status. Only full papers were included in the analysis. Within these studies cannabis legal status was rarely considered. Recruitment strategies did not include any attempt to rule out prohibition effects except for Weiland and cols, 2015. No study directly characterized cannabis consumed by subjects. We considered if information such as the source of cannabis, mode of acquisition, contact with criminal activity or policing activities at supply sites, and contamination were added as possible confounding factors, or at least acknowledged as relevant but ignored variables. All studies had some manner of control for frequency or amount used. However, no attention was given for details pertaining to drug experience under prohibition, such as level of stress, acquisition strategies, parental or social deceit, delivery mode and route. Addiction was not included in our analysis since in some studies this was a criterion for subject selection. The majority of studies made some form of policy recommendation. such as age or potency restrictions, public health educational programs, and others; when social and health implications were discussed without direct advice, we labeled it as in part. NA, not applicable. 


\begin{tabular}{|c|c|c|c|c|c|c|}
\hline Study & Subject selection & $\begin{array}{l}\text { Cannabis } \\
\text { characterization }\end{array}$ & Frequency and amount & Drug experience & $\begin{array}{l}\text { Prohibition } \\
\text { discussed }\end{array}$ & $\begin{array}{l}\text { Policy } \\
\text { recommendations }\end{array}$ \\
\hline Marconi 2016 & NA, review only & $\begin{array}{l}\text { Potency and } \\
\text { phytochemical profile }\end{array}$ & Self-report; interview & Not discussed & No & Yes \\
\hline Tien 1990 & Survey & None & Self-report; interview & Not discussed & No & Yes \\
\hline Degenhardt 2001 & Survey & None & Self-report; interview & Not discussed & No & Yes \\
\hline Arseneault 2002 & Cohort study & None & Self-report & Not discussed & No & Yes \\
\hline Zammit 2002 & Cohort study & None & Self-report & Not discussed & No & Yes \\
\hline Henquet 2005 & Cohort study & None & Self-report; interview & Not discussed & No & No \\
\hline Wiles 2006 & Survey & None & Self-report; interview & Not discussed & No & In part \\
\hline Miettunen 2008 & Cohort study & None & Questionnaire & Not discussed & No & No \\
\hline Mcgrath 2010 & Cohort study & None & Questionnaire & Not discussed & No & In part \\
\hline Zammit 2011 & Cohort study & None & Self-report & Not discussed & No & Yes \\
\hline Diforti 2014 & Hospital entry; structured interview & $\begin{array}{l}\text { Potency and } \\
\text { phytochemical profile }\end{array}$ & Self-report; interview & Not discussed & No & Yes \\
\hline Diforti 2009 & Hospital entry; survey; public ads & $\begin{array}{l}\text { Potency and } \\
\text { phytochemical profile }\end{array}$ & Self-report; interview & Not discussed & No & Yes \\
\hline Weiland 2015 & $\begin{array}{l}\text { Recruited from general population } \\
\text { and juvenile court }\end{array}$ & None & Self-report; interview & $\begin{array}{l}\text { Law-conflicts } \\
\text { considered }\end{array}$ & Yes & Yes \\
\hline Block 2000 & General population ads. & None & $\begin{array}{l}\text { Self-report; interview; urine } \\
\text { test pre-screen }\end{array}$ & Not discussed & No & No \\
\hline Tzilos 2005 & General population ads. & None & Interview & Not discussed & No & No \\
\hline Yucel 2008 & General population ads. & None & Interview, urine analysis & $\begin{array}{l}\text { Consumption } \\
\text { quantity, duration, } \\
\text { and method }\end{array}$ & No & In part \\
\hline Medina 2007 & High schools, universities, ads. & None & Interview & Not discussed & No & No \\
\hline Medina 2007b & High schools, universities, ads. & None & Interview; urine analysis & Not discussed & No & No \\
\hline Medina 2010 & Local schools via fliers distribution & None & Interview; urine analysis & Not discussed & No & No \\
\hline Solowij 2011 & $\begin{array}{l}\text { Recruited from general population } \\
\text { and referral }\end{array}$ & None & Interview; urine analysis & Not discussed & No & Yes \\
\hline Ashtari 2011 & $\begin{array}{l}\text { Recruited from a therapeutic } \\
\text { community }\end{array}$ & None & Self-report; toxicology & Not discussed & No & Yes \\
\hline Mcqueeny 2011 & Local schools & None & Self-report; questionnaire & Anxiety scores & No & Yes \\
\hline Cousijin 2012 & Internet and coffeshops ads. & None & $\begin{array}{l}\text { Self-report; urine analysis; } \\
\text { interview }\end{array}$ & Not discussed & No & In part \\
\hline Gilman 2014 & Recruitment not described & None & $\begin{array}{l}\text { Self-report; urine analysis; } \\
\text { interview }\end{array}$ & $\begin{array}{l}\text { Pattern of use; } \\
\text { Anxiety scores }\end{array}$ & No & Yes \\
\hline
\end{tabular}

